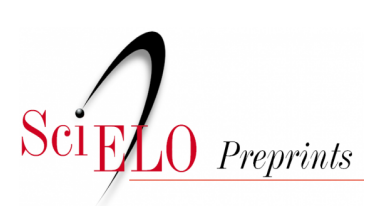

Situação: O preprint foi submetido para publicação em um periódico

\title{
Casos de tuberculose com notificação após o óbito no Brasil, 2014: um estudo descritivo com base nos dados de vigilância
}

Ursila Manga Aridja, Luciana Guerra Gallo, Ana Flávia de Morais Oliveira, Andressa Wanneska Martins da Silva, Elisabeth Carmen Duarte

DOI: $10.1590 / S c i E L O P r e p r i n t s .1222$

Este preprint foi submetido sob as seguintes condições:

- O autor submissor declara que todos os autores responsáveis pela elaboração do manuscrito concordam com este depósito.

- Os autores declaram que estão cientes que são os únicos responsáveis pelo conteúdo do preprint e que o depósito no SciELO Preprints não significa nenhum compromisso de parte do SciELO, exceto sua preservação e disseminação.

- Os autores declaram que a pesquisa que deu origem ao manuscrito seguiu as boas práticas éticas e que as necessárias aprovações de comitês de ética de pesquisa estão descritas no manuscrito, quando aplicável.

- Os autores declaram que os necessários Termos de Consentimento Livre e Esclarecido de participantes ou pacientes na pesquisa foram obtidos e estão descritos no manuscrito, quando aplicável.

- Os autores declaram que a elaboração do manuscrito seguiu as normas éticas de comunicação científica.

- Os autores declaram que o manuscrito não foi depositado e/ou disponibilizado previamente em outro servidor de preprints.

- Os autores declaram que no caso deste manuscrito ter sido submetido previamente a um periódico e estando o mesmo em avaliação receberam consentimento do periódico para realizar o depósito no servidor SciELO Preprints.

- O autor submissor declara que as contribuições de todos os autores estão incluídas no manuscrito.

- O manuscrito depositado está no formato PDF.

- Os autores declaram que caso o manuscrito venha a ser postado no servidor SciELO Preprints, o mesmo estará disponível sob licença Creative Commons CC-BY.

- Caso o manuscrito esteja em processo de revisão e publicação por um periódico, os autores declaram que receberam autorização do periódico para realizar este depósito.

Submetido em (AAAA-MM-DD): 2020-09-20

Postado em (AAAA-MM-DD): 2020-09-21 


\section{Epidemiologia}

e Serviços de Saúde

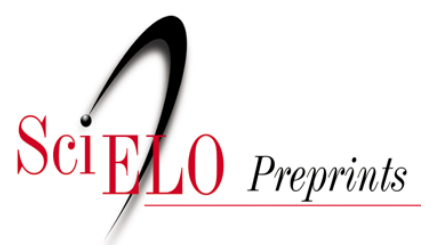

Como citar este artigo:

Aridja UM, Gallo LG, Oliveira AFM, Silva AWM, Duarte EC. Casos de tuberculose com notificação após o óbito no Brasil, 2014: um estudo descritivo com base nos dados de vigilância. Epidemiol Serv Saúde [preprint]. 2020 [citado 2020 set 9]:[22

p.]. Disponível em: http://dx.doi.org/10.1590/S1679-49742020000500014

Artigo original

Casos de tuberculose com notificação após o óbito no Brasil, 2014: um estudo descritivo com base nos dados de vigilância*

Tuberculosis cases with post mortem notification in Brazil, 2014: a descriptive study based on surveillance data

Casos de tuberculosis notificados después de la muerte en Brasil, 2014: un estudio descriptivo basado en datos de vigilancia

Ursila Manga Aridja ${ }^{1}$ - orcid.org/0000-0001-8322-1025;

Luciana Guerra Gallo1 - orcid.org/0000-0001-8344-9951_

Ana Flávia de Morais Oliveira1 - orcid.org/0000-0003-3210-1618_

Andressa Wanneska Martins da Silva ${ }^{1}$ - orcid.org/0000-0002-3868-9873

Elisabeth Carmen Duarte ${ }^{1}$ - orcid.org/0000-0001-9148-5063

${ }^{1}$ Universidade de Brasília, Programa de Pós-Graduação em Medicina Tropical, Brasília, DF, Brasil 
*Artigo derivado de dissertação de Mestrado intitulada 'Casos de tuberculose com notificação pós-óbito: caracterização e fatores associados - Brasil, 2014', defendida por Ursila Manga Aridja junto ao Programa de Pós-Graduação em Medicina Trópical, área de concentração Epidemiologia e Controle das Doenças Infecciosas e Parasítárias, Universidade de Brasília (UnB), em março de 2020.

\section{Endereço para correspondência:}

Ursila Manga Aridja - Colina, Bloco K, Apto. 106-A, Asa Norte, Brasília, DF, Brasil. CEP: 70910-900

E-mail: ursilamanga@gmail.com

Recebido em 04/04/2020

Aprovado em 18/08/2020

Editora associada: Bárbara Reis-Santos - orcid.org/0000-0001-6952-0352

\section{Resumo}

Objetivo. Caracterizar os casos com notificação pós-óbito da tuberculose no Brasil em 2014. Métodos. Estudo descritivo dos casos de tuberculose com notificação pós-óbito. Os dados são resultantes da vinculação do Sistema de Informação de Agravos de Notificação (Sinan-TB) com o Sistema de Informações sobre Mortalidade (SIM), e foram descritos segundo causa básica de óbito: tuberculose, aids e outras. Resultados. Nos 2.703 casos de tuberculose com notificação pós-óbito, observou-se maior proporção de pessoas do sexo masculino (73,5\%), com mais de 39 anos de idade (80,8\%), com escolaridade $<8$ anos de estudo (66,5\%), de raça/cor da pele negra e parda $(62,8 \%)$, que adoeceram de tuberculose na forma clínica pulmonar $(75,2 \%)$; também prevaleceram notificações pelo serviço público $(57,6 \%)$ e em municípios com índice de desenvolvimento humano $>0,7(66,6 \%)$. Conclusão. As características descritas das pessoas notificadas pós-óbito e a magnitude desse desfecho sugerem fragilidades dos serviços de atenção e vigilância da tuberculose

Palavras-chave: Tuberculose; Notificação de Doenças; Epidemiologia Descritiva; Mortalidade; Sistemas de Informação. 


\begin{abstract}
Objective. To characterize cases with post-mortem notification of Tuberculosis in Brazil, in 2014. Methods. This is a descriptive study of tuberculosis cases with postmortem notification. Data were resulted from the linkage of the Notifiable Diseases Information System-TB (Sinan-TB) and the Mortality Information System (SIM); and were described according to the underlying cause of death: TB, AIDS and others. Results. 2,703 tuberculosis cases had post-mortem notification in Brazil in 2014. There were a high proportion of male (73.5\%), age over 39(80.8\%), <8 years of education $(66.5 \%)$, black \& brown ethnicity $(62.8 \%)$, pulmonary clinic form $(75.2 \%)$, notified by public health service (57.6\%) and from municipalities with MHDI $>0.7$ (66.6\%). Conclusion. The described characteristics of people with post-mortem notification and the magnitude of this outcome suggest weaknesses in tuberculosis care and surveillance services.
\end{abstract}

Keywords: Tuberculosis; Disease Notification; Descriptive Epidemiology; Mortality; Information Systems.

\title{
Introdução
}

A tuberculose continua a ser a principal causa de morte entre as doenças infecciosas e uma das dez principais causas de morte em todo o mundo, onde, em 2018, foram estimados 10 milhões de casos e 1,4 milhão de mortes diretamente relacionadas a ela, a TB. ${ }^{1}$

Em 2018, as Américas contribuíram com 3\% da carga global da TB, e o Brasil ocupou a primeira posição do continente, com 32\% dos casos, seguido pelo Peru (13\%) e México (10\%). Segundo a Organização Mundial da Saúde (OMS), o Brasil foi o único do continente americano listado entre os 30 países com alta carga de TB que respondem por $87 \%$ de todos os casos notificados e apresentam uma taxa de incidência estimada em 45 casos por 100 mil habitantes. ${ }^{1}$ No mesmo ano, o Sistema de Informação de Agravos de Notificação-TB (Sinan-TB) do Departamento de Doenças de Condições Crônicas e Infecções Sexualmente Transmissíveis do Ministério da Saúde do Brasil (DCCI/MS), 
registrou 75.717 novos casos de TB (36,2 casos por 100 mil hab.), sendo 423 casos notificados após o óbito. ${ }^{2}$

A TB é uma doença de notificação obrigatória no Brasil. ${ }^{3}$ Existe uma rede de grande capilaridade para a vigilância e controle da doença, presente em todos os municípios brasileiros, que implementam diferentes estratégias e tecnologias para prevenir novos casos e reduzir a carga da doença. ${ }^{2}$ Porém, uma situação merecedora de preocupação resiste em permanecer: parte da população com TB não é captada pelos serviços de vigilância e atenção dessa rede.

A não detecção de casos de TB é um importante desafio a enfrentar, porque contribui para a manutenção da cadeia de transmissão, impede o tratamento efetivo e permite subestimar a magnitude do problema para a Saúde Pública. ${ }^{4,5}$ A notificação pós-óbito de um caso de TB pode ser considerada 'evento sentinela' que denuncia falha no atendimento individual e compromete a efetividade do serviço de controle da doença

Dessa forma, o objetivo deste estudo foi caracterizar os casos com notificação pós-óbito da TB no Brasil em 2014.

\section{Métodos}

Trata-se de um estudo descritivo dos casos de TB com notificação pós-óbito, encontrados a partir do relacionamento do Sinan-TB com o Sistema de Informações sobre Mortalidade (SIM), ambos do Ministério da Saúde, sobre dados referentes ao ano de 2014.

O Brasil é um país de dimensões continentais, ocupa uma área territorial de $8.510 .820,623 \mathrm{~km}^{2}$ e somava uma população estimada em 204,2 milhões de hab. em 2014. ${ }^{6}$ Existe uma grande desigualdade social no país, especialmente desfavorável às regiões Norte e Nordeste, que apresentam a renda media per capita e o índice de Gini mais baixos entre as cinco grandes regiões brasileiras. ${ }^{7,8}$ No mesmo ano de 2014, a TB foi considerada uma das doenças de maior importância para a Saúde Pública: ${ }^{9}$ foram registrado 67.966 casos novos naquele período, com maiores coeficientes de incidência observados nos estados do Amazonas (68,4/100 mil hab.) e do Rio de Janeiro (60.9/100 mil hab.), ${ }^{10} \mathrm{e}$, em nível nacional, uma mortalidade de 2,4 óbitos por 100 mil hab. ${ }^{11}$ 
Cumpre lembrar que o sistema de saúde brasileiro - o Sistema Único de Saúde (SUS) atende o maior contingente populacional do país, é público e gratuito, de cobertura universal. ${ }^{12}$ Ainda em 2014, a rede de serviços da administração pública - federal, estadual e municipal - detinha cerca de 898.612 serviços vinculados ao SUS. ${ }^{13}$

A população de estudo foi composta por todos os casos de TB com notificação pós-óbito no Brasil, em 2014. Os critérios de exclusão de casos foram: idade menor que 15 anos, para prevenir grande heterogeneidade na população de estudo; e ausência de informação sobre sexo.

A notificação pós-óbito foi definida como uma notificação do caso de TB exclusivamente realizada nas circunstâncias do óbito.

As informações referentes à população do estudo foram identificadas a partir de um banco de dados secundários, resultante de um processo de relacionamento do Sinan-TB com o SIM, disponível apenas para o ano de 2014. Para o presente estudo, foram somados os casos encontrados no Sinan-TB com tipo de entrada 'pós-óbito' àqueles encontrados exclusivamente no SIM, estes também considerados 'pós-óbito' no presente estudo. No SIM, a TB deveria constar como causa básica ou como condição contribuinte da morte registrada na Parte I ou na Parte II de CAUSAS DA MORTE, na Declaração de Óbito (DO), referida pelos códigos A15 a A19 da 10a Revisão da Classificação Estatística Internacional de Doenças e Problemas Relacionados à Saúde (CID-10).

O banco de dados relacionado, SIM + Sinan-TB, foi disponibilizado pelo Ministério da Saúde após solicitação realizada via Sistema Eletrônico de Informações ao Cidadão (eSIC), no sítio virtual http://esic.cgu.gov.br/sistema/site/index.aspx (Protocolo $\mathrm{n}^{\mathrm{o}}$ 25820.004488/2019-30, emitido em 6 de junho de 2019).

As variáveis de interesse do estudo foram:

a) Características individuais

- Sexo (masculino; feminino)

- Faixa etária (anos: 15 a 19; 20 a 39; 40 a 59; 60 ou mais)

- Escolaridade (anos de estudo: nenhum; 1 a 8; mais de 8; ignorada)

- Raça/cor da pele (branca; preta ou parda; indígena; ignorada)

- Forma clínica da tuberculose (pulmonar [pulmonar; pulmonar + extrapulmonar]; extrapulmonar ou SOE [sem menção da confirmação bacteriológica ou histológica]) 
- Causa básica de morte (TB; aids; outras)

- Presença (não; sim) de outras doenças mencionadas na DO - doenças crônicas selecionadas (diabetes mellitus [E10-14], hipertensão [I10-15], doenças do aparelho respiratório [J00-99], entre outras) e doenças que tiveram maior número de menções nas notificações pós-óbito.

b) Características do município de residência

- Índice de desenvolvimento humano (IDHM) (baixo [menos de 0,6]; médio [0,6 a $0,7]$; alto [mais de 0,7])

- Porcentagem de pobreza (baixa [menos de 10\%]; média [10 a 20\%], alta [20 a 45\%]; muita alta [mais de 45\%]). A porcentagem de pobreza foi definida como a proporção de indivíduos com renda domiciliar per capita igual ou inferior a $\mathrm{R} \$ 140,00$ mensais, em agosto de 2010.

- Porte populacional (número de habitantes: pequeno [menos de 20 mil]; médio [20 a 100 mil]; grande [mais de 100 mil])

- Macrorregião nacional (Norte; Nordeste; Sudeste; Sul, Centro-Oeste)

- Município de residência (foram descritos os dez municípios com mais casos de notificação pós-óbito)

c) Características do tipo de serviço

- Assistência médica para a doença que causou o óbito (não; sim)

- Tipo de serviço de saúde que notificou o óbito (público; privado; sem fins lucrativos; não especificado)

- Cobertura da Estratégia Saúde da Família (ESF) (baixa [até 50\%]; média [50 a 75\%]; alta [acima de 75\%]) no município de residência

- Cobertura de Atenção Básica (AB) (baixa [até 50\%]; média [50 a 75\%]; alta [acima de 75\%]) no município de residência

As variáveis referentes às características do município de residência foram retiradas da fundação Instituto Brasileiro de Geografia e Estatística (IBGE) e do Programa das Nações Unidas para o Desenvolvimento (PNUD) (2013), e as referentes às características dos serviços de saúde, do Tabnet (e-Gestor). ${ }^{6,14,15}$ Todas as demais variáveis são originadas do SIM.

A equipe técnica do DCCI/MS efetuou o relacionamento probabilístico, pelo software livre Reclink III, ${ }^{16}$ aplicando uma rotina de múltiplos passos, cada um deles empregando 
uma determinada chave de blocagem. ${ }^{4} \mathrm{O}$ relacionamento probabilístico é composto por uma etapa de padronização, cujo objetivo é uniformizar os arquivos para posterior utilização. A etapa seguinte, propriamente chamada de 'relacionamento', é composta por dois processos, blocagem e pareamento dos registros, os quais auxiliam na otimização do processo de comparação, dividindo as bases de dados em blocos lógicos, e na construção de escores, a partir de uma determinada estratégia de blocagem empregada. No estudo em tela, os parâmetros de relacionamento foram estimados mediante aplicação de algoritmos Expectation-Maximization (EM). A última etapa, de combinação dos dados, propõe-se à criação de um novo arquivo, baseado em dois outros, sendo os pares considerados "verdadeiros" são identificados segundo o escore definido, mediante conferência dos nomes completos da pessoa, da mãe, e da data de nascimento. A cada passo de blocagem, fez-se uma revisão manual. Os registros duvidosos foram classificados como 'não pares'.

Foram descritas as frequências absolutas e relativas das variáveis de interesse, com auxílio dos softwares Stata versão 11.0 e Microsoft Office Excel 2013.

O estudo respeitou os preceitos éticos para condução de pesquisa com seres humanos. Uma vez que se utilizou, exclusivamente, dados secundários não nominais, de acesso público, não houve a necessidade da aprovação de um Comitê de Ética em Pesquisa (CEP).

\section{Resultados}

Identificou-se um total de 7.268 óbitos com menção a TB em 2014 (Figura 1). Deles foram excluídos 4.447 casos de TB notificados regularmente no Sinan, 59 casos com idade menor que 15 anos e 59 casos sem informação sobre sexo (Figura 1). As notificações pós-óbito (2.703) foram resultantes da soma de 2.506 (93\%) casos registrados exclusivamente no SIM e 197 (7\%) oriundos do Sinan-TB com tipo de entrada 'pós-óbito'. A TB, como causa básica, contribuiu com $64,9 \%$ de todas as mortes; e a aids, como causa básica, com 19,7\%. 
A maioria dos casos com notificação pós-óbito de TB como causa básica foi de pessoas do sexo masculino (73,5\%), com mais de 39 anos de idade $(80,8 \%)$, de baixa escolaridade ( 8 anos ou menos de estudo, $66,5 \%)$, de raça/cor da pele preta ou parda $(62,8 \%)$ e com a forma clínica pulmonar da infecção $(75,2 \%)$ (Tabela 1). Diferentemente das duas outras causas básicas destacadas no estudo, pessoas coinfectadas com aids + TB (aids como causa básica do óbito) apresentaram proporções menos expressivas do sexo masculino $(68,6 \%)$, idade superior a 39 anos $(53,9 \%)$, baixa escolaridade $(60,8 \%)$ e menor contribuição da forma clínica pulmonar da TB (57,2\%) (Tabela 1).

As mortes por TB como causa básica, com notificação pós-óbito, ocorreram, principalmente, em residentes de municípios com alto IDHM (66,6\%), grande porte populacional $(59,6 \%)$, baixa ou média porcentagem de pobreza $(72,9 \%)$, situados nas regiões Sudeste $(46,4 \%)$ e Nordeste $(32,6 \%)$ do país (Tabela 2$)$.

Entre as principais enfermidades contribuintes, quando a TB era a causa básica do óbito, foram identificadas doenças do aparelho respiratório (52,7\%), transtornos mentais e comportamentais, causados por uso de psicoativo (10,0\%), doenças do sistema circulatório $(8,9 \%)$, desnutrição $(6,4 \%)$, doenças do aparelho digestivo $(5,1 \%)$, hipertensão $(4,4 \%)$, diabetes mellitus $(4,0 \%)$ e doenças do aparelho geniturinário $(3,9 \%)$ (Figura 2). Entre as doenças respiratórias, destacaram-se as crônicas do trato respiratório inferior. Quando a TB aparecia como causa associada, as neoplasias malignas figuraram entre as mais frequentes causas básicas de óbito, e entretanto, com menor frequência como causas associadas (2,1\%) (Figura 2$)$.

Para a quase totalidade dos casos estudados ( $>90 \%)$, não foi possível identificar se a pessoa teve acesso a assistência médica para a condição que gerou o óbito (Tabela 3). Casos atendidos no serviço público de saúde foram responsáveis por cerca da metade ou mais das notificações de TB pós-óbito, para os três grupos de causas básicas do óbito (TB; aids; outras). Finalmente, mais da metade dos casos foi notificada em municípios com baixa cobertura da ESF (54,2\%), embora com média ou alta cobertura de $\mathrm{AB}$, de $42,1 \%$ e $35,3 \%$ respectivamente (Tabela 3 ).

\section{Discussão}


O estudo encontrou elevado número de casos de TB com notificação identificada apenas no pós-óbito, resgatados principalmente do SIM, não incluídos, portanto, nas estatísticas oficiais do DCCI/MS. Os casos de TB notificados após o óbito apresentaram a TB e a aids como as principais causas básicas do óbito. Observou-se, entre as notificações pósóbito de TB, maiores proporções de pessoas do sexo masculino, de idade acima dos 39 anos, com oito anos ou menos de estudo, de raça/cor da pele preta ou parda, com a forma clínica pulmonar, e notificadas pelo serviço público de saúde. Além disso, seus municípios de residência referiam maior IDHM, baixa taxa de pobreza, grande porte populacional, baixa cobertura da Estratégia Saúde da Família e alta ou média cobertura da Atenção Básica.

A proporção de coinfecção aids + TB, seja como causa básica, seja como causa associada, corrobora estudos prévios, segundo os quais a aids aparece como a segunda causa de morte entre todas as pessoas com TB. ${ }^{1,17}$ Esse resultado é preocupante, quando o protocolo adotado no país recomenda a testagem para TB de toda pessoa com HIV, assim como o inverso. ${ }^{18}$

Foi observada maior proporção do sexo masculino entre os casos de TB com notificação pós-óbito. É sabido que homens são mais acometidos pela TB e morrem mais por essa causa, comparados às mulheres, o que pode estar relacionado ao fato de eles procurarem menos os serviços de saúde, aderirem menos ao tratamento e apresentarem mais fatores de risco, entre outras razões. ${ }^{119}$ Estudos apontam que o sexo masculino também está mais sujeito a subnotificação de casos. Pinheiro et al ${ }^{20}$ avaliaram a subnotificação da TB em um município do Rio de Janeiro e identificaram maior subnotificação entre a população masculina.

Maior frequência de pessoas com 60 anos de idade ou mais foi identificada entre as notificações pós-óbito de TB, quando comparada à das demais faixas etárias. Muitos estudos demonstram que pessoas em idade produtiva tendem a apresentar elevada incidência da TB, apontando a maior efetividade do alerta para a detecção de casos nesse grupo etário.,17,21-23 Entretanto, a maior vulnerabilidade biológica dos idosos, especialmente relacionada à presença de outras doenças, incrementa o risco de morte por TB nessa idade, mascara sintomas da doença, reduz o alerta para o diagnóstico precoce e 
retarda o tratamento, dando oportunidade para subnotificação e notificação pós-óbito da TB.

Pessoas pretas ou pardas contribuíram com mais de $60 \%$ de todas as notificações pósóbito de TB, segundo este estudo. Além de ser o grupo étnico-racial com maior contingente populacional no Brasil, a variável raça/cor da pele preta ou parda tem importante colinearidade com escolaridade e renda no país, e portanto, associa-se com o padrão de busca por serviços de saúde. ${ }^{6,24,25}$ Pessoas pretas e pardas estão, assim, mais expostas ao atraso do diagnóstico e tratamento, e da notificação oportuna da doença. $\mathrm{O}$ resultado do estudo corrobora essa hipótese e evidencia as barreiras enfrentadas por esse contingente no acesso à saúde de qualidade no Brasil, um dos países mais desiguais do mundo. ${ }^{26}$

A forma clínica pulmonar da TB, a mais frequente no Brasil, ${ }^{5}$ contribuiu com a maior parte dos casos notificados pós-óbito, como se verificou. Pessoas com TB pulmonar e notificação apenas no pós-óbito são ainda assim preocupantes, devido a seu potencial de transmissão, muito embora haja disponibilidade de testes diagnósticos acurados e tratamento efetivo gratuito, em todo o país, para prover melhor prognóstico que outras formas clínicas. ${ }^{27}$

Contudo, os casos com TB extrapulmonar foram mais frequentes entre pessoas coinfectadas com HIV/aids. É conhecida a forte associação entre TB extrapulmonar e infecção por HIV. ${ }^{6,28}$ Em geral, é maior a dificuldade do diagnóstico dessa forma clínica da TB, mais ainda em pessoas com HIV, o que favorece a sub-detecção da TB nessa população e justifica, em parte, os resultados encontrados.

Os municípios com alto IDHM, grande porte populacional e baixa taxa de pobreza, principalmente aqueles situados nas regiões Sudeste e Nordeste, possuem grandes contingentes populacionais para justificar o maior número de casos de TB em todas as subcategorias, inclusive entre os casos com notificações pós-óbito. ${ }^{6,29}$ Vale lembrar que, não obstante seus elevados IDHMs, esses grandes municípios também apresentam grandes desigualdades sociais e contingente elevado de populações vulneráveis, contribuindo sobremaneira com as demandas não atendidas pelos serviços de saúde e, por conseguinte, maior possibilidade de casos com notificação pós-óbito.

Na população estudada, quando a TB foi uma causa associada, as principais causas básicas identificadas foram aids, doenças do aparelho respiratório, doenças circulatórias, 
neoplasias malignas, doenças do aparelho digestivo, transtornos mentais e comportamentais, hipertensão e diabetes mellitus, nesta ordem. Essa lista - é importante notar - apresenta doenças que demandam cuidados e acompanhamento contínuos dos profissionais de saúde. Esses achados confirmam a observação feita no estudo do Rocha et al.: ${ }^{17}$ ao caracterizarem as causas múltiplas de morte de uma coorte de casos notificados, esses autores encontraram doenças associadas semelhantes às supracitadas. Esse resultado permite inferir sobre falhas na integralidade do cuidado, e sobre perdas de oportunidades para o diagnóstico e manejo de pessoas com TB e seus contatos.

Pessoas atendidas em serviços de saúde públicos, no momento do óbito, foram responsáveis pela maior proporção de notificação pós-óbito de TB (sendo a TB a causa básica da morte ou não). Isto pode ser explicado pelo fato de o serviço público ser gratuito e sua cobertura nacional, e consequentemente, abranger a maior parte da população. ${ }^{11}$ Outrossim, pessoas atendidas nesses serviços possuem, em média, maior vulnerabilidade social, o que pode ter contribuído para a alta parcela de notificações de TB apenas após o óbito.

Casos residentes em municípios com baixa cobertura da Estratégia Saúde da Família e baixa ou média cobertura da Atenção Básica contribuíram com alta proporção de notificação pós-óbito da TB. Essa situação pode refletir a população exposta a essas coberturas, uma vez que municípios maiores tendem a ter baixas coberturas desse tipo de atenção à saúde, especialmente da ESF. Além disso, esses resultados podem revelar territórios onde a porta de entrada no SUS não se dá, efetivamente, pela Atenção Primária à Saúde, comprometendo a ordenação do cuidado, assim como o adequado manejo e vigilância da TB. Fortalecer a Atenção Básica como estratégia de ordenação da atenção à saúde deve contribuir para o enfrentamento do problema e possivelmente, reduzir a subdetecção e subnotificação de casos de TB nos municípios. De fato, segundo Rasella et al., ${ }^{30}$ municípios com altas coberturas da ESF e da AB apresentam melhores indicadores de saúde.

A principal limitação deste trabalho está relacionada ao uso de dados secundários da rotina do sistema de vigilância em saúde. Dados incompletos, não acurados, e falta de padronização no preenchimento das notificações e Declaraç ões de Óbito - DO -, entre outras falhas, podem favorecer vieses/erros de informação. Contudo, o SIM do Brasil é reconhecido como um sistema robusto, de cobertura acima de 95\% dos óbitos 
estimados. ${ }^{29}$ Outra limitação do estudo reside em ter considerado, como notificações pósóbito, todos os casos notificados no Sinan com essa classificação e aqueles notificados exclusivamente no SIM, com base em pareamento probabilístico. O processo de relacionamento dos dois sistemas de informações pode ter falhado na identificação de todos os pares verdadeiros, permitindo a classificação errônea de caso como notificação pós-óbito. Isto poderia ter contribuído para uma superestimativa de casos. Finalmente, a população do estudo pode representar tanto (i) os indivíduos com acesso adequado ao diagnóstico e tratamento da TB, porém subnotificados pelo Sinan, quanto (ii) os indivíduos sem nenhum acesso a assistência em TB. Sendo assim, outra limitação consistiria na dificuldade em discriminar essas diferentes situações e melhor compreender os achados descritos. Todavia, o perfil de vulnerabilidade das pessoas identificadas nos leva a acreditar na segunda situação como a mais provável.

O estudo caracterizou pessoas que tiveram notificação pós-óbito da TB no Brasil, em 2014, seu perfil sociodemográfico e clínico, as características dos municípios de residência e outras variáveis selecionadas. A hipótese destas autoras é de que pessoas notificadas somente após o óbito são casos de TB subnotificados e, provavelmente, subdetectados, seja por dificuldade de diagnóstico, seja de acesso aos serviços de saúde. De qualquer forma, essas situações revelam uma fragilidade na qualidade da atenção recebida. Apesar de a TB ser uma doença tratável e evitável, em 2014, 2.703 pessoas foram diagnosticadas após o óbito e, provavelmente, não tiveram seus contatos alcançados pelos serviços de vigilância, o que confere relevância epidemiológica aos achados. É possível que esses casos reflitam importante perda de oportunidade, por parte do sistema de saúde, haja vista uma parcela relevante dos casos de TB notificados pósóbito terem pelo menos uma condição crônica que, supostamente, demandasse acompanhamento contínuo.

Conclui-se, dos resultados apresentados, a necessidade de aperfeiçoamento da vigilância da TB no Brasil. É mister estimular o interesse pelo estudo dos fatores de risco associados ao diagnóstico e notificação pós-óbito dos casos de TB, com o objetivo de identificar como esses sujeitos se diferenciam daqueles que tiveram uma notificação regular. Esse tipo de abordagem pode auxiliar na formulação de estratégias e políticas de vigilância, visando aumentar a identificação oportuna de pacientes com tuberculose. 


\section{Contribuição das autoras}

Aridja UM e Duarte EC contribuíram com a concepção e delineamento do estudo, análise e interpretação dos resultados, redação e revisão crítica do conteúdo do manuscrito. Oliveira AFM, Silva AWM e Gallo LG contribuíram com a redação, interpretação dos resultados, crítica do conteúdo intelectual e revisão do manuscrito. Todas as autoras aprovaram a versão final do manuscrito e são responsáveis por todos seus aspectos, incluindo a garantia de sua precisão e integridade.

\section{Referências}

1. World Health Organization - WHO. Global tuberculosis report 2019 [Internet]. Geneva: World Health Organization; 2019 [cited 2020 Jan 1]. 283 p. Available from: https://apps.who.int/iris/bitstream/handle/10665/329368/9789241565714eng.pdf?ua $=1$

2. Ministério da Saúde (BR). Secretaria de Vigilância em Saúde. Tuberculose 2020. Bol Epidemiol [Internet]. 2020 mar [citado 2020 abr 2];número especial. Disponível em: https://www.saude.gov.br/images/pdf/2020/marco/24/Boletimtuberculose-2020-marcas--1-.pdf

3. Brasil. Ministério da Saúde. Portaria MS/GM n ${ }^{0}$ 204, de 17 de fevereiro de 2016. Define a Lista Nacional de Notificação Compulsória de doenças, agravos e eventos de saúde pública [Internet]. Diário Oficial da União, Brasília (DF), 2016 fev 18 [citado 2020 set 9];Seção I:23. Disponível em: http://bvsms.saude.gov.br/bvs/saudelegis/gm/2016/prt0204_17_02_2016.html

4. Santos ML, Coeli CM, Batista JAL, Braga MC, Albuquerque MFPM. Fatores associados à subnotificação de tuberculose com base no Sinan Aids e Sinan Tuberculose. Rev Bras Epidemiol [Internet]. 2018 [citado 2020 set 7];21:e180019. Disponível em: https://doi.org/10.1590/1980-549720180019

5. Ministério da Saúde (BR). Secretaria de Vigilância em Saúde. Protocolo para vigilância do óbito com menção de tuberculose nas causas de morte [Internet]. Brasília: Ministério da Saúde; 2017 [citado 2020 jan 10]. Disponível em: http://dive.sc.gov.br/conteudos/publicacoes/Protocolo-para-Vigilncia-doobito.pdf

6. Instituto Brasileiro de Geografia e Estatística - IBGE. População Census 2010 [Internet]. Rio de Janeiro: Instituto Brasileiro de Geografia e Estatística; 2011 [citado 2019 nov 9]. Disponível em: https://www.ibge.gov.br/en/statistics/social/labor/18391-2010-populationcensus.html? $=\& \mathrm{t}=\mathrm{o}-\mathrm{que}-\mathrm{e}$ 
7. Ministério da Saúde (BR). Departamento de Informática do SUS - Datasus.

Definições [Internet]. Brasília: Ministério da Saúde; 2020 [citado 2020 maio 2].

Disponível em:

http://tabnet.datasus.gov.br/cgi/tabcgi.exe?ibge/censo/cnv/rendauf.def

8. Ministério da Saúde (BR). Departamento de Informática do SUS - Datasus.

Definições [Internet]. Brasília: Ministério da Saúde; 2020 [citado 2020 maio 2].

Disponível em: http://tabnet.datasus.gov.br/cgi/ibge/censo/cnv/giniuf.def

9. Ministério da Saúde (BR). Secretaria de Vigilância em Saúde. Departamento de Vigilância de Doenças não Transmissíveis e Promoção da Saúde. Saúde Brasil 2014: uma análise de situação de saúde e das causas externas [Internet]. Brasília: Ministério da Saúde; 2015 [citado 2020 set 7]. 462 p. Disponível em: https://bvsms.saude.gov.br/bvs/publicacoes/saude_brasil_2014_analise_situacao. pdf

10. Ministério da Saúde (BR). Secretaria de Vigilância em Saúde. Departamento de Vigilância Epidemiológico. Detectar, tratar e curar: desa os e estratégias brasileiras frente à tuberculose. Bol Epidemiol [Internet]. 2015 [citado 2020 set 7];46(9). Disponível em:

https://portalarquivos.saude.gov.br/images/pdf/2015/marco/25/Boletimtuberculose-2015.pdf

11. Ministério da Saúde (BR). Secretaria de Vigilância em Saúde. Departamento de Vigilância Epidemioloógico. Perspectivas brasileiras para o $\mathrm{m}$ da tuberculose como problema de saúde pública. Bol Epidemiol [Internet]. 2016 [citado 2020 set 7];47(13). Disponível em:

http://www.saude.gov.br/images/pdf/2016/marco/24/2016-009-Tuberculose001.pdf

12. Viacava F, Oliveira RAD, Carvalho CC, Laguardia J, Bellido JG. SUS: oferta, acesso e utilização de serviços de saúde nos últimos 30 anos. Ciênc Saúde Coletiva [internet]. 2018 [citado 2020 jan 10];23(6):1751-62. Disponível em: https://doi.org/10.1590/1413-81232018236.06022018

13. Ministério da Saúde (BR). Departamento de Informática do SUS - Datasus. Definições - CNES estabelecimentos por tipo - Brasil [Internet]. Brasília: Ministério da Saúde; 2020 [citado 2020 maio 2]. Disponível em: http://tabnet.datasus.gov.br/cgi/tabcgi.exe?cnes/cnv/estabbr.def

14. Programa das Nações Unidas para o Desenvolvimento - PNUD. Fundação João Ribeiro. Instituto de Pesquisa Econômica Aplicada. Desenvolvimento humano para além das médias [Internet]. Brasília: PNUD; 2017 [citado 2020 jan 10]. 127 p. Disponível em:

https://www.undp.org/content/dam/brazil/docs/IDH/desenvolvimento-alem-dasmedias.pdf

15. Ministério da Saúde (BR). e-Gestor Atenção Básica. Informação e Gestão da Atenção Básica. Cobertura da atenção básica [Internet]. Brasília: Ministério da Saúde; 2020 [citado 2020 jan 10]. Disponível em: https://egestorab.saude.gov.br/paginas/acessoPublico/relatorios/relHistoricoCobe rturaAB.xhtml 
16. Camargo Júnior KR, Coeli CM. Reclink: an application for database linkage implementing the probabilistic record linkage method. Cad Saúde Pública [Internet]. 2000 Apr-Jun [cited 2020 Sep 7];16(2):439-47. Available from: https://doi.org/10.1590/S0102-311X2000000200014

17. Rocha MS, Oliveira GP, Aguiar FP, Saraceni V, Pinheiro RS. Do que morrem os pacientes com tuberculose: causas múltiplas de morte de uma coorte de casos notificados e uma proposta de investigação de causas presumíveis. Cad Saúde Pública [Internet]. 2015 abr [citado 2020 set 7];31(4):709-21. Disponível em: https://doi.org/10.1590/0102-311X00101214

18. Ministério da Saúde (BR). Secretaria Executiva. Recomendação para o manejo da coinfecção TB-HIV em serviços de atenção especializada à pessoas vivendo com HIV/AIDS [Internet]. Brasília: Ministério da Saúde; 2013 [citado 2020 abr 20]. 28 p. Disponível em:

https://bvsms.saude.gov.br/bvs/publicacoes/recomendacoes_manejo_coinfeccao_ tb_hiv.pdf

19. Teixeira DBS, Cruz SPL. Atenção à saúde do homem: análise da sua resistência na procura dos serviços de saúde. Rev Cuba Enferm [Internet]. 2016 [citado 2020 mar 26];32(4). Disponible en:

http://www.revenfermeria.sld.cu/index.php/enf/article/view/985/209

20. Pinheiro RS, Andrade VL, Oliveira GP. Subnotificação da tuberculose no Sistema de Informação de Agravos de Notificação (SINAN): abandono primário de bacilíferos e captação de casos em outras fontes de informação usando linkage probabilístico. Cad Saúde Pública [Internet]. 2012 ago [citado 2020 set 7];28(8): 1559-68. Disponível em: http://dx.doi.org/10.1590/S0102-311X2012000800014

21. Lacerda TC, Souza FM, Prado TN, Locatelli RL, Fregona G, Lima RCD, et al. Infecção por tuberculose entre profissionais de saúde da atenção básica. J Bras Pneumol [Internet]. $2017 \mathrm{dez}$ [citado 2020 set 7];43(6):416-23. Disponível em: https://doi.org/10.1590/s1806-37562016000000211

22. Reis-Santos B, Shete P, Bertolde A, Sales CM, Sanchez MN, Arakaki-Sanchez D, et al. Tuberculosis in Brazil and cash transfer programs: A longitudinal database study of the effect of cash transfer on cure rates. PLoS One [Internet]. 2019 Feb [cited 2019 Nov 10];14(2):e0212617. Available from: http://dx.plos.org/10.1371/journal.pone.0212617

23. Freire ILS, Santos FR, Menezes LCC, Medeiros AB, Lima RF, Silva BCO. Adesão dos idosos às formas de administração do tratamento da tuberculose. J Res Fundam Care Online [Internet]. 2019 abr-jul [citado 2020 set 7];11(3):555-9. Disponível em: http://www.seer.unirio.br/index.php/cuidadofundamental/article/view/6493/pdf_1

24. Oliveira JE, Ferrari AP, Tonete VLP, Parada CMGL. Perinatal results and firstyear of life according to maternal skin color: a cohort study. Rev Esc Enferm USP [Internet]. 2019 Jul [cited 2020 Sep 7];53:e03480. Available from: https://doi.org/10.1590/s1980-220x2018003903480

25. Berquó E. Demografia e desigualdade: algumas considerações sobre negros no Brasil. In: Anais do VI Encontro Nacional de Estudos Populacionais [Internet]; 
1988 out 16-20; Olinda, PE. [S.1]: Associação Brasileira de Estudos Populacionais;1988 [citado 2020 jan 10]. p. 89-110. Disponível em: http://www.abep.org.br/publicacoes/index.php/anais/article/viewFile/479/463

26. The World Bank. GINI index (World Bank estimate) [Internet]. [S.1.]: The World Bank Group; 2019 [cited 2020 Jan 10]. Available from:

https://data.worldbank.org/indicator/SI.POV.GINI?view=map\&year=2016

27. Ferreira SRS, Glasenapp R, Flores R. Tuberculose na atenção primaria à saúde [Internet]. Brasília: Ministério da Saúde; 2011 [citado 2020 abr 13]. 130 p. Disponível em:

http://www.mobilizadores.org.br/wpcontent/uploads/2014/05/livro_tuberculose 1 1.pdf

28. Bates M, Mudenda V, Shibemba A, Kaluwaji J, Tembo J, Kabwe M, et al. Burden of tuberculosis at post mortem in inpatients at a tertiary referral centre in sub-Saharan Africa: a prospective descriptive autopsy study. Lancet Infect Dis [Internet]. 2015 May [cited 2020 Sep 7];15(5):544-51. Available from: http://dx.doi.org/10.1016/S1473-3099(15)70058-7

29. Ministério da Saúde (BR). Secretaria de Vigilância em Saúde. Departamento de Vigilância Epidemioloógico. Vigilância em saúde no Brasil 2003 | 2019. Bol Epidemiol [Internet]. 2019 set [citado 2020 set 7];número especial. Disponível em: https://portalarquivos2.saude.gov.br/images/pdf/2019/setembro/25/boletimespecial-21ago19-web.pdf

30. Rasella D, Harhay MO, Pamponet ML, Aquino R, Barreto ML. Impact of primary health care on mortality from heart and cerebrovascular diseases in Brazil: A nationwide analysis of longitudinal data. BMJ [Internet]. 2014 Jul [cited 2020 Sep 7];349:g4014. Available from:

http://dx.doi.org/doi:10.1136/bmj.g4014 


\section{Tabelas e Figuras}

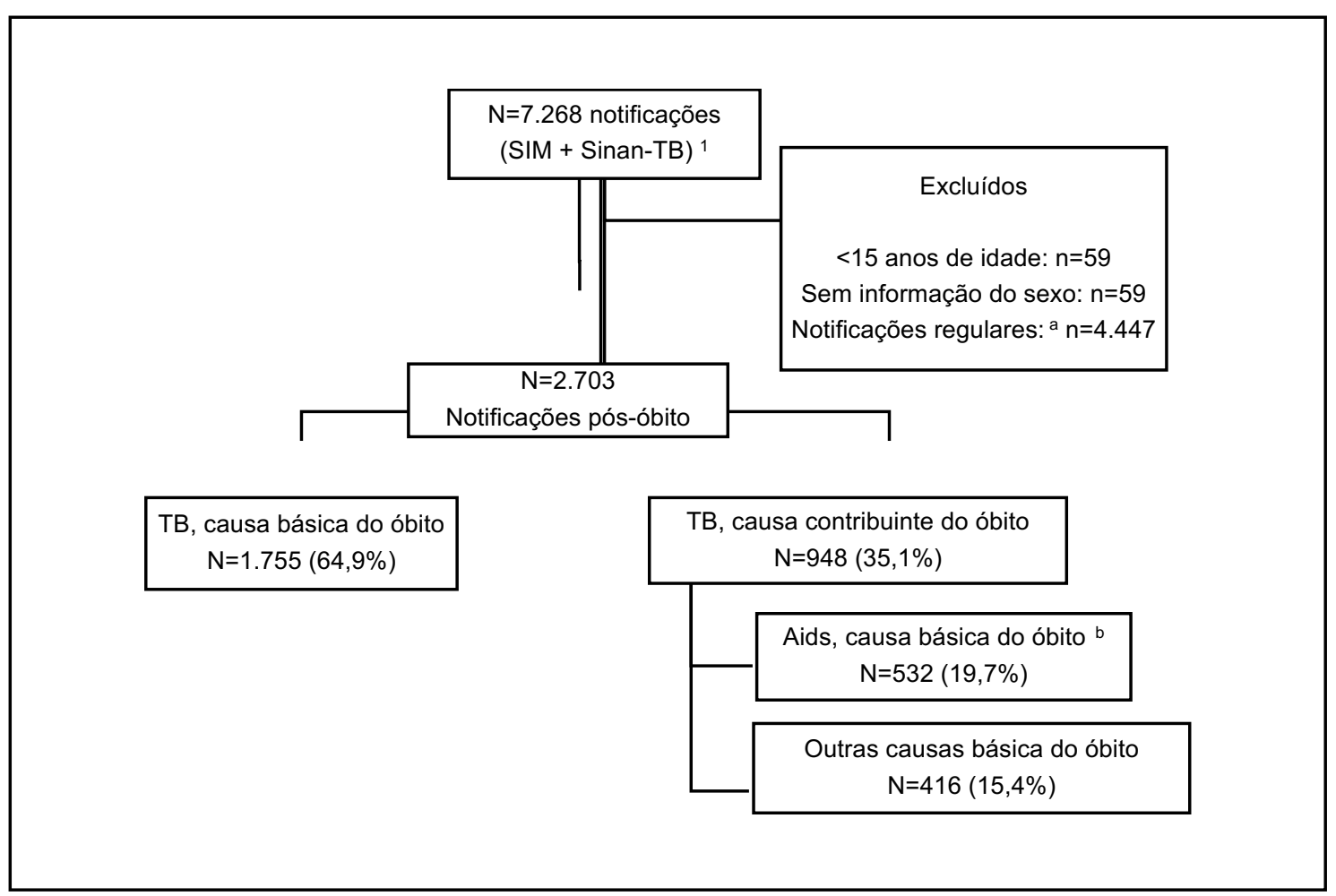

Legenda:

Aids: síndrome da imunodeficiência adquirida (sigla em inglês, para Acquired Immunodeficiency Virus). SIM: Sistema de Informações sobre Mortalidade.

Sinan-TB: Sistema de Informação de Agravos de Notificação - Tuberculose.

TB: tuberculose.

a) Casos notificados antes do óbito.

b) Coinfecção aids + TB.

Figura 1 - Fluxograma de seleção dos casos de tuberculose com notificação pós-

óbito, Brasil, 2014 
Tabela 1 - Distribuição absoluta e relativa das características individuais e da forma clínica dos casos com menção a tuberculose notificados pós-óbito, segundo causa básica, Brasil, 2014

\begin{tabular}{|c|c|c|c|c|}
\hline \multirow{3}{*}{ Características } & \multirow{3}{*}{$\begin{array}{l}\text { TB, causa básica } \\
\text { do óbito } \\
\text { N (\%) }\end{array}$} & \multicolumn{2}{|c|}{ TB, causa contribuinte de óbito } & \multirow{3}{*}{$\begin{array}{c}\text { Total } \\
\text { N }\end{array}$} \\
\hline & & $\begin{array}{l}\text { Aids, causa básica } \\
\text { do óbito }\end{array}$ & $\begin{array}{l}\text { Outras causas } \\
\text { básicas do óbito }\end{array}$ & \\
\hline & & $\mathbf{N}(\%)$ & $\mathbf{N}(\%)$ & \\
\hline \multicolumn{5}{|l|}{ Sexo } \\
\hline Feminino & $465(26,5)$ & $167(31,4)$ & $108(25,9)$ & 740 \\
\hline Masculino & $1.290(73,5)$ & $365(68,6)$ & $308(74,1)$ & 1.963 \\
\hline \multicolumn{5}{|c|}{ Faixa etária (anos) } \\
\hline $15-20$ & $19(1,1)$ & $3(0,6)$ & $6(1,4)$ & 28 \\
\hline 20-39 & $317(18,1)$ & $242(45,5)$ & $63(15,2)$ & 622 \\
\hline $40-59$ & $676(38,5)$ & $250(47,0)$ & $154(37,0)$ & 1.080 \\
\hline$\geq 60$ & $743(42,3)$ & $37(6,9)$ & $193(46,4)$ & 973 \\
\hline \multicolumn{5}{|c|}{ Escolaridade (anos de estudo) } \\
\hline 0 & $311(17,7)$ & $48(9,1)$ & $59(14,2)$ & 418 \\
\hline $1-8$ & $857(48,8)$ & $275(51,7)$ & $221(53,1)$ & 1.353 \\
\hline$>8$ & $212(12,1)$ & $101(18,9)$ & $56(13,5)$ & 369 \\
\hline Ignorada & $375(21,4)$ & $108(20,3)$ & $80(19,2)$ & 563 \\
\hline \multicolumn{5}{|l|}{ Raça/cor da pele } \\
\hline Branca & $567(32,3)$ & $173(32,5)$ & $144(34,6)$ & 884 \\
\hline Preta ou parda & $1.101(62,8)$ & $333(62,6)$ & $253(60,8)$ & 1.687 \\
\hline Indígena & $18(1,0)$ & $2(0,4)$ & $2(0,5)$ & 22 \\
\hline Ignorada & $69(3,9)$ & $24(4,5)$ & $17(4,1)$ & 110 \\
\hline \multicolumn{5}{|c|}{ Forma clínica da tuberculose } \\
\hline Pulmonar & $1.320(75,2)$ & $304(57,2)$ & $280(67,3)$ & 1.904 \\
\hline $\mathrm{SOE}^{\mathrm{a}}$ & $259(14,8)$ & $115(21,6)$ & $100(24,1)$ & 474 \\
\hline Extrapulmonar & $176(10,0)$ & $113(21,2)$ & $36(8,6)$ & 325 \\
\hline Total & $1.755(100,0)$ & $532(100,0)$ & $416(100,0)$ & 2.703 \\
\hline
\end{tabular}

Legenda:

Aids: síndrome da imunodeficiência adquirida (sigla em inglês, para Acquired Immunodeficiency Virus).

SIM: Sistema de Informações sobre Mortalidade.

TB: tuberculose.

a) SOE: forma clínica da tuberculose sem menção de confirmação bacteriológica ou histológica. 
Tabela 2 - Distribuição absoluta e relativa das características dos municípios de residência dos casos com menção a tuberculose notificados pós-óbito, segundo causa básica, Brasil, 2014

\begin{tabular}{|c|c|c|c|c|}
\hline \multirow{3}{*}{ Características } & \multirow{3}{*}{$\begin{array}{c}\text { TB, causa básica } \\
\text { do óbito } \\
\text { N (\%) }\end{array}$} & \multicolumn{2}{|c|}{ TB, causa contribuinte do óbito } & \multirow{3}{*}{$\begin{array}{l}\text { Total } \\
\mathbf{N}\end{array}$} \\
\hline & & $\begin{array}{c}\text { Aids, causa básica } \\
\text { do óbito }\end{array}$ & $\begin{array}{c}\text { Outras causas } \\
\text { básicas do óbito }\end{array}$ & \\
\hline & & $\mathbf{N}(\%)$ & $\mathbf{N}(\%)$ & \\
\hline \multicolumn{5}{|l|}{ IDHM } \\
\hline Ignorado & $21(1,2)$ & $6(1,1)$ & $2(0,5)$ & 29 \\
\hline Baixo $(<0,6)$ & $192(10,9)$ & $22(4,2)$ & $43(10,3)$ & 257 \\
\hline Médio $(0,6-0,7)$ & $373(21,3)$ & $105(19,7)$ & $70(16,8)$ & 548 \\
\hline Alto $(>0,7)$ & $1.169(66,6)$ & $399(75,0)$ & $301(72,4)$ & 1.869 \\
\hline \multicolumn{5}{|l|}{ Pobreza (\%) } \\
\hline Ignorado & $21(1,2)$ & $6(1,1)$ & $2(0,5)$ & 29 \\
\hline Baixa $(<10)$ & $831(47,4)$ & $307(57,7)$ & $216(51,9)$ & 1.354 \\
\hline Média (10-20) & $448(25,5)$ & $142(26,7)$ & $108(25,9)$ & 698 \\
\hline Alta $(20-45)$ & $271(15,4)$ & $54(10,2)$ & $49(11,8)$ & 374 \\
\hline Muita alta $(>45)$ & $184(10,5)$ & $23(4,3)$ & $41(9,9)$ & 248 \\
\hline \multicolumn{5}{|c|}{ Porte populacional (por mil hab.) } \\
\hline Ignorado & $21(1,2)$ & $6(1,1)$ & $2(0,5)$ & 29 \\
\hline Pequeno (<20 mil) & $268(15,3)$ & $46(8,6)$ & $61(14,7)$ & 375 \\
\hline Médio (20-100 mil) & $420(23,9)$ & $120(22,6)$ & $98(23,5)$ & 638 \\
\hline Grande (>100 mil) & $1.046(59,6)$ & $360(67,7)$ & $255(61,3)$ & 1.661 \\
\hline \multicolumn{5}{|l|}{ Região de residência } \\
\hline Norte & $208(11,8)$ & $59(11,1)$ & $40(9,6)$ & 307 \\
\hline Nordeste & $572(32,6)$ & $121(22,7)$ & $147(35,4)$ & 840 \\
\hline Sudeste & $815(46,4)$ & $244(45,9)$ & $174(41,8)$ & 1.233 \\
\hline Sul & $87(5,0)$ & $78(14,7)$ & $33(7,9)$ & 198 \\
\hline Centro-Oeste & $73(4,2)$ & $30(5,6)$ & $22(5,3)$ & 125 \\
\hline \multicolumn{5}{|c|}{ Municípios de residência } \\
\hline Rio de Janeiro & $199(11,3)$ & $54(10,2)$ & $41(9,9)$ & 294 \\
\hline São Paulo & $144(8,2)$ & $31(5,8)$ & $25(6,0)$ & 200 \\
\hline Porto Alegre & - & $7(1,3)$ & $5(1,2)$ & 12 \\
\hline Recife & $21(1,2)$ & $9(1,7)$ & $4(1,0)$ & 34 \\
\hline Manaus & $27(1,5)$ & $9(1,7)$ & $6(1,4)$ & 42 \\
\hline Salvador & $43(2,5)$ & $16(3,0)$ & $15(3,6)$ & 74 \\
\hline
\end{tabular}




\begin{tabular}{lcccc}
\hline Fortaleza & $26(1,5)$ & $6(1,1)$ & $20(4,8)$ & 52 \\
Belém & $47(2,7)$ & $12(2,3)$ & $10(2,4)$ & 69 \\
Demais capitais/municípios $^{\mathbf{a}}$ & $96(5,5)$ & $46(8,6)$ & $27(6,5)$ & 169 \\
Demais municípios & $1.152(65,6)$ & $342(64,3)$ & $263(63,2)$ & 1.757 \\
\hline Total & $\mathbf{1 . 7 5 5 ( 1 0 0 , 0 )}$ & $\mathbf{5 3 2}(\mathbf{1 0 0 , 0})$ & $\mathbf{4 1 6 ( 1 0 0 , 0 )}$ & $\mathbf{2 . 7 0 3}$ \\
\hline
\end{tabular}

Legenda:

Aids: síndrome da imunodeficiência adquirida (sigla em inglês, para Acquired Immunodeficiency Virus).

IDHM: índice de desenvolvimento humano municipal.

TB: tuberculose.

a) Demais municípios que também são capitais.

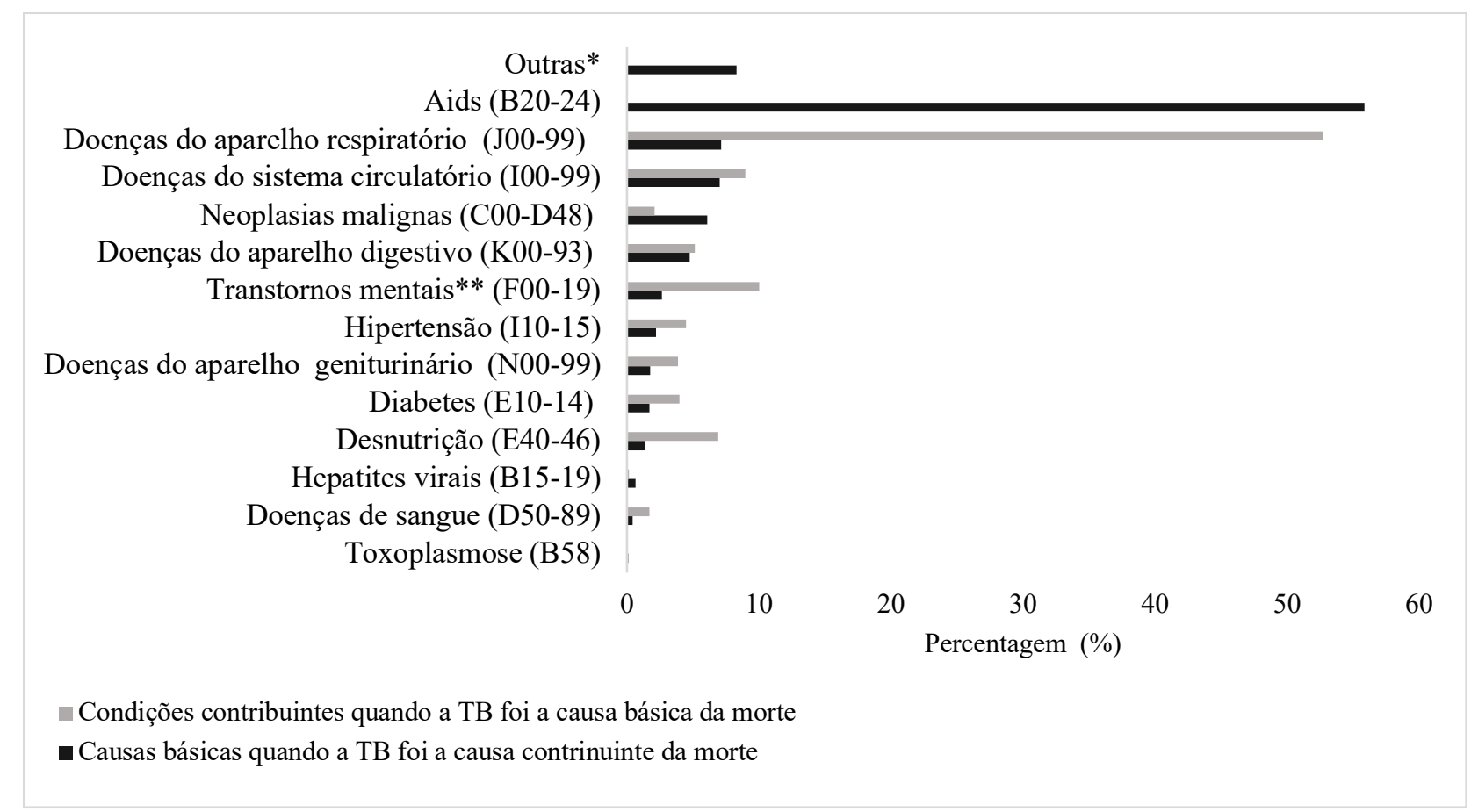

* Mortalidade por: causa externa, doenças mal definidas e causas desconhecidas, e doenças não crônicas.

** Transtornos mentais e comportamentais devido ao uso de psicoativos.

a) Foram escolhidas as doenças crônicas que apresentaram maior frequência de notificação pós-óbito.

Figura 2 - Distribuição (\%) de causas básicas e associadas de óbito selecionadasa dos casos com menção a tuberculose notificados pós-óbito, Brasil, 2014 
Tabela 3 - Distribuição absoluta e relativa das características da assistência à saúde e dos serviços de saúde nos municípios de residência de casos de tuberculose pós-óbito, segundo causa básica, Brasil, 2014

\begin{tabular}{lccccc}
\hline & & \multicolumn{3}{c}{ TB, causa contribuinte do óbito } \\
\cline { 3 - 4 } Características & TB, causa básica do & óbito & $\begin{array}{c}\text { Aids, causa } \\
\text { básica do óbito }\end{array}$ & $\begin{array}{c}\text { Outras causas } \\
\text { básicas do óbito }\end{array}$ & Total \\
& & $\mathrm{N}(\%)$ & $\mathrm{N}(\%)$ & $\mathrm{N}(\%)$ & $\mathrm{N}$ \\
\hline
\end{tabular}

Nível individual

\begin{tabular}{lcccc}
\hline \multicolumn{4}{l}{ Assistência médica $^{\mathbf{a}^{\mathbf{l}}}$} & \multicolumn{5}{l}{} \\
\hline Sim & $68(3,9)$ & $13(2,4)$ & $5(1,2)$ & 86 \\
Não & $23(1,3)$ & $3(0,6)$ & $6(1,4)$ & 32 \\
Ignorado & $1.664(94,8)$ & $516(97)$ & $405(97,4)$ & 2.585 \\
\hline Tipo de serviço de saúde que notificou o óbito & & & & \\
\hline Público & $1.011(57,6)$ & $364(68,4)$ & $204(49,0)$ & 1.579 \\
Privado & $85(4,8)$ & $29(5,4)$ & $39(9,4)$ & 153 \\
Sem fins lucrativos & $261(14,9)$ & $95(17,9)$ & $81(19,5)$ & 437 \\
Ignorado & $398(22,7)$ & $44(8,3)$ & $92(22,1)$ & 534 \\
\hline
\end{tabular}

Nível municipal

\begin{tabular}{|c|c|c|c|c|}
\hline \multicolumn{5}{|c|}{ Cobertura da ESF } \\
\hline Baixa $(<50)$ & $952(54,2)$ & $321(60,3)$ & $226(54,3)$ & 1.499 \\
\hline Média (50-75) & $324(18,5)$ & $91(17,1)$ & $61(14,7)$ & 476 \\
\hline Alta $(>75)$ & $479(27,3)$ & $120(22,6)$ & $129(31,0)$ & 728 \\
\hline \multicolumn{5}{|c|}{ Cobertura da $\mathbf{A B}^{\mathrm{c}}$} \\
\hline Baixa $(<50)$ & $397(22,6)$ & $228(42,9)$ & $85(20,4)$ & 710 \\
\hline Média (50-75) & $739(42,1)$ & $165(31,0)$ & $170(40,9)$ & 1.074 \\
\hline Alta $(>75)$ & $619(35,3)$ & $139(26,1)$ & $161(38,7)$ & 919 \\
\hline Total & $1.755(100,0)$ & $532(100,0)$ & $416(100,0)$ & 2.703 \\
\hline
\end{tabular}
a) Assistência médica para a doença que gerou o óbito, conforme notificado na Declaração de Óbito (DO).
b) ESF: Estratégia Saúde da Família.
c) AB: Atenção Básica em Saúde. 